\title{
Null Mutation of c-fos Impairs Structural and Functional Plasticities in the Kindling Model of Epilepsy
}

\author{
Yoshinori Watanabe, ${ }^{1}$ Randall S. Johnson, ${ }^{2}$ Linda S. Butler, ${ }^{1}$ Devin K. Binder, ${ }^{3}$ Bruce M. Spiegelman, ${ }^{2}$ \\ Virginia E. Papaioannou, ${ }^{4}$ and James O. McNamara ${ }^{1,3,5}$ \\ ${ }^{1}$ Department of Medicine (Neurology), Epilepsy Research Laboratory, Duke University Medical Center, Durham, North \\ Carolina 27710, 2 Dana-Farber Cancer Institute, Departments of Biological Chemistry and Molecular Pharmacology, \\ Hanard Medical School, Boston, Massachusetts 02115, 32Departments of Neurobiology and Pharmacology, Duke \\ University Medical Center, Durham, North Carolina 27710, ${ }^{4}$ Department of Genetics and Development, College of \\ Physicians and Surgeons, Columbia University, New York, New York 10032, and 5Veterans Affairs Medical Center, \\ Durham, North Carolina 27705
}

It has been suggested that expression of the immediate early gene c-fos links fleeting changes in neuronal activity to lasting modifications of neuronal structure and function in the mammalian nervous system. To test this idea, we examined behavioral and electrophysiological indices of kindling development and kindling-induced sprouting of hippocampal granule cell axons in wild-type $(+/+)$, heterozygous $(+/-)$, and homozygous $(-/-)$ mice carrying a null mutation of $c$-fos. The rate of kindling development was significantly attenuated in $-/-$ compared with $+/+$ mice, as evidenced by both electrophysiological and behavioral measures. Kindling-induced granule cell axon sprouting as measured by the Timm stain was also attenuated in homozygous null mutants compared with $+/+$ mice, with an intermediate effect in $+1-$ mice. The impairment of kindling-induced axonal sprouting in the null mutants could not be attributed to either detectable loss of dentate hilar neurons or reduced activation of the dentate granule cells by seizures. Instead, our data are consistent with the hypothesis that the null mutation of c-fos attenuates a pathological activitydetermined functional plasticity (kindling development) as well as a structural plasticity (mossy fiber reorganization). We favor the hypothesis that this "fos-less phenotype" is attributable to impaired seizure-induced transcriptional activation of one or more growth-related genes.

Key words: c-fos; immediate early genes; kindling; axonal reorganization; epilepsy; plasticity
Alterations in neuronal activity produce a lasting reorganization of synaptic connections in the mammalian nervous system (Hubel and Wiesel, 1965). Patterned activity is critical to the formation of normal synaptic connections in the developing nervous system (Cline and Constantine-Paton, 1990; Shatz, 1990), and excess neuronal activity also contributes to the formation of abnormal synaptic connections in the mature nervous system (Sutula et al., 1988; Represa et al., 1993). Kindling is a model of epilepsy in which fleeting changes of neuronal activity in the form of brief focal seizures lead to lifelong structural and functional reorganization of the mammalian brain. Kindling is induced most conveniently by focal application of a low-intensity electrical stimulus that initially evokes a brief, localized electrical seizure without behavioral change; however, after repeated applications it evokes prolonged, widespread electrical seizures accompanied by intense behavioral seizures (Goddard et al., 1969; McNamara et al., 1993). Once established, this enhanced sensitivity to electrical stimulation is lifelong. Kindling is accompanied by lasting synaptic reorganization exemplified by the aberrant synapses formed by mossy fiber axons of the hippocampal dentate granule cells (Sutula et al., 1988; Represa et al., 1993); the activity-dependence of this reorganization was demonstrated by its preferential induc-

\footnotetext{
Received Jan. 23, 1996; revised March 25, 1996; accepted April 2, 1996.

We thank Dr. L. Lerca for expert technical assistance. This work was supported by National Institutes of Health Grants HD24926 (R.S.J., B.M.S.), HD27295 (R.S.J., B.M.S., V.E.P.), NS17771 (J.O.M.), and NS32334 (J.O.M.).

Correspondence should be addressed to Dr. James O. McNamara, 401 Bryan Research Building, Duke University Medical Center, Durham, NC 27710.

Copyright 11996 Society for Neuroscience $0270-6474 / 96 / 163827-10 \$ 05.00 / 0$
}

tion by high-frequency compared to low-frequency stimulation of neurons that activate the granule cells (Sutula et al., 1988).

Immediate early genes (IEGs) such as c-fos provide an attractive mechanism by which fleeting changes of neuronal activity may produce lifelong structural and functional changes via regulation of gene expression. Circumstantial evidence suggests that c-fos in particular is part of a chain of molecular events that culminate in outgrowth of dentate granule cell axons in seizure models. Seizures are sufficient to induce the transcriptional activation of c-fos and other IEGs (Morgan and Curran, 1991; Kiessling and Gass, 1993; Labiner et al., 1993) in the dentate granule cells, followed shortly thereafter by expression of genes encoding neurotrophic factors [e.g., nerve growth factor (NGF), brain-derived neurotrophic factor (BDNF), basic fibroblast growth factor (bFGF)] (Gall and Isackson, 1989; Ernfors et al., 1991; Gall, 1993; Gall et al., 1994), neurotrophic factor receptors (e.g., Trk B, FGFR-1) (Bengzon et al., 1993; Bugra et al., 1994), and axonal growthassociated proteins such as GAP-43 (Bendotti et al., 1993; Meberg et al., 1993). Because neurotrophic factors exert morphoregulatory effects on hippocampal neurons (Walicke et al., 1986; Mattson et al., 1989; Ip et al., 1993; Patel and McNamara, 1995), seizure-induced expression of these genes may underlie the morphological rearrangements of granule cell axons. The presence of AP-1 sites in the promoter region of several of these growthrelated genes (e.g., bFGF and GAP-43) (Shibata et al., 1991; Nedivi et al., 1992) suggests that they may be IEG target genes contributing to the lasting synaptic reorganization of the granule cells in kindling. 
The development of a null mutation of the c-fos protooncogene in transgenic mice by gene targeting (Johnson et al., 1992; Wang et al., 1992) provides an experimental preparation in which the role of c-fos in the structural and functional plasticities of the kindling model can be assessed. The goal of these experiments was to examine behavioral and electrophysiological indices of kindling development and the kindling-induced sprouting of the mossy fiber axons of the dentate granule cells in wild-type $(+/+)$, heterozygous $(+/-)$, and homozygous $(-/-)$ mice carrying a null mutation for c-fos. We show that indeed the development of both kindling and kindling-induced mossy fiber sprouting are impaired in $\mathrm{c}$-fos $-1-$ mice.

\section{MATERIALS AND METHODS}

Kindling and surgical procedures. Animals used in this study $(n=63)$ were progeny of a cross between C57BL/6J and $129 / \mathrm{SvJ}$ mice that were homozygous wild-type $(+/+)$, heterozygous $(+/-)$, or homozygous mutant $(-/-)$ for the targeted $c$-fos allele (Johnson et al., 1992). Mice of all three genotypes underwent stereotaxic implantation of a bipolar electrode in the right amygdala under pentobarbital anesthesia using the following coordinates with bregma as reference: $0.5 \mathrm{~mm}$ posterior; $2.7 \mathrm{~mm}$ lateral; $4.5 \mathrm{~mm}$ below dura. A ground wire was attached to a screw overlying the lefi frontal cortex in all implanted animals $(n=37)$. In a subset of these animals $(n=12)$, electrographic seizure activity was recorded from an additional bipolar recording electrode placed in the right hippocampus using the following stereotaxic coordinates relative to bregma: $2.4 \mathrm{~mm}$ posterior; $2.0 \mathrm{~mm}$ lateral; $1.7 \mathrm{~mm}$ below dura. Animals used for Timm staining and morphometric studies of hippocampus were selected from the subset without hippocampal electrodes because of the potential confounding factors arising from injury. After a postoperative recovery period of at least 1 week, the afterdischarge threshold (AD) was determined by application of a series of $1 \mathrm{sec}$ trains of $60 \mathrm{~Hz} 1 \mathrm{msec}$ biphasic rectangular pulses beginning at a current intensity of $40 \mu \mathrm{A}$ followed by trains of increasing current intensity administered at 1 min intervals until an $A D$ of at least $3 \mathrm{sec}$ was observed. Seizures were classified according to a modification of Racine (1972): 1, chewing; 2, head-nodding; 3, urilateral forelimb clonus; 4 , bilateral forelimb clonus; 5 , bilateral forelimb clonus plus falling and/or hindlimb clonus; 6 , running or bouncing seizure; and 7, tonic hindiimb extension. Animals were stimulated twice daily with interstimulus intervals of at least $4 \mathrm{hr}$ until at least 10 class 4 or 5 seizures were evoked, each of which had clonic or tonic activity of at least $12 \mathrm{sec}$. At least 10 class 4 or 5 seizures were evoked before the animals were killed to enhance mossy fiber sprouting and facilitate comparison of sprouting among $+/+,+/-$, and $-1-$ mice. To assure objectivity in interpretation of electrophysiological data, the electroencephalographs (EEGs) were coded and the duration of AD was ascertained by an observer who was unaware of the genotype of the subject; this was performed for the subset of the animals (Figs. 2, 4) used for Timm staining and morphometric analyses. No differences between the blinded and unblinded analyses were found.

Histologic analyses. To prepare brains for histologic analysis, a subset of the animals examined for kindling development were perfused transcardially under deep pentobarbital anesthesia at least $3 \mathrm{~d}$ after the last stimulation-evoked clonic motor seizure. The perfusion was performed at room temperature at a flow rate of $6 \mathrm{ml} / \mathrm{min}$. The perfusion was initiated with a $0.16 \%$ solution of $0.1 \mathrm{M}$ sodium phosphate-buffered sodium sulfate, $\mathrm{pH} 7.4$, for $4 \mathrm{~min}$, followed by $0.1 \mathrm{~m}$ sodium phosphate-buffered fixative solution of $3 \%$ glutaraldehyde, $\mathrm{pH} \mathrm{7.4,} \mathrm{for} 10 \mathrm{~min}$. Animals underwent perfusion at least $3 \mathrm{~d}$ after the last stimulation-evoked clonic motor seizure. Only satisfactorily perfused animals were used for image analysis. Criteria for a satisfactory perfusion were that both forelimbs and hindlimbs were symmetrically stiffened by perfusion and the brain was rendered symmetrically firm by perfusion. Satisfactory perfusions were obtained in seven $+/+$, five $+/-$, and four $-1-$ mice after kindling and in seven $+/+$, five $+/-$, and four $-/-$ unstimulated mice; these brains were used to assess mossy fiber sprouting and morphometric study of the dentate hilus. After perfusion, the brain was immersed for $4 \mathrm{hr}$ in the fixative buffer at $4{ }^{\circ} \mathrm{C}$. After fixation, the brain was immersed in $15 \%$

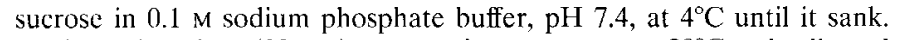
Horizontal sections $(20 \mu \mathrm{m})$ were cut in a cryostat at $-20^{\circ} \mathrm{C}$ and collected in $0.05 \mathrm{M}$ Tris- $\mathrm{HCl}$ buffer, $\mathrm{pH} 7.6$.

Timm staining refers to a histochemical technique that labels synaptic terminals of the mossy fiber axons of the dentate granule cells; this was used to measure the sprouting of these axons into the supragranular region that accompanies amygdaloid kindling (Cavazos et al., 1991). Serial sections were collected between 1900 and $2800 \mu \mathrm{m}$ ventral to the dorsal surface of the brain, and the sections were mounted on gelatincoated slides and developed in the dark for $90-120 \mathrm{~min}$ in a 5:1 mixture of gum arabic $(20 \% \mathrm{w} / \mathrm{v})$ and hydroquinonc solution $(2 \% \mathrm{w} / \mathrm{v})$ containing citric acid $(3 \% \mathrm{w} / \mathrm{v})$ and silver nitrate $(0.9 \% \mathrm{w} / \mathrm{v})$. To minimize the influence of variation of tissue thickness and of precise horizontal level, analyses were performed on four serial sections through the septal region of the dentate gyrus from each animal collected between 2000 and 2080 $\mu \mathrm{m}$ ventral from the surface of the neocortex. To facilitate meaningful comparison of sections of different animals, slides from $+/+,+/-$, and $-1-$ animals were included in the same slide rack and exposed to the same solutions for the same duration of time. To assure objectivity in data analysis, slides subsequently were coded and subjected to image analysis by an observer who was unaware of the genotype or treatment of the animal.

The area within the supragranular region occupied by the Timm granules was determined by using a computer-assisted image analyzer (Image-1, Universal Imaging) attached to a light microscope (Zeiss ICM 405) with a high-resolution CCD camera. The assessment of sprouting was obtaincd from the absolute value of the total area of Timm granules divided by the total length of the dentate gyrus (Timm index). For each animal, the absolute value of the Timm index is the mean of the four scctions.

Measures of hilar neuron number, density, and volume were performed as follows. Between 2800 and $46000 \mu \mathrm{m}$ ventral from the dorsal surface of neocortex, every third section was stained with cresyl violet, coded, and studied with a computer-assisted image analyzer (Neurolucida, MicroBrightField) attached to a light microscope (Nikon FXA) with a highresolution CCD camera. The area of the hilus $\left(A\right.$ in $\left.\mu \mathrm{m}^{2}\right)$ was defined in each section as the area contained within boundaries of lines drawn along the hilar margin of the dentate granule cell layer and from the tips of the granule cell layer to the termination of the CA3c pyramidal cell layer within the hilus. The total volume $\left(V_{\mathrm{T}}\right)$ of the hilus in $\mu \mathrm{m}^{3}=\left(A_{1}+A_{2}+\right.$ $\left.A_{3} \ldots+A_{30}\right) \times 20 \mu \mathrm{m}$. Cell number $(N)$ was determined for each section on the video monitor image by counting each cell with a nucleus containing a nucleolus evident in the hilus field. The total cell number $\left(N_{\mathrm{T}}\right)=\left(N_{1}+N_{2}+N_{3} \ldots+N_{30}\right)$. Thus hilus cell density $=N_{\mathrm{T}} \div V_{\mathrm{T}}$ for each hilus (analyzed separately for ipsilateral and contralateral hilus). Electrode placements were determined by a blinded observer in sections stained with methyl green-pyronine $\mathrm{Y}$ or cresyl violet. Animals in which the electrodes were not clearly located in the amygdala (and also in the hippocampus in the subset of animals in which such electrodes were directed) were excluded from further analysis.

Riboprobe preparation. Plasmids containing the full-length rat c-fos cDNA insert (generously supplied by J. Morgan and T. Curran, Roche Institute of Molecular Biology, Nutley, NJ) in antisense or sense orientation were used to generate antisense and sense c-fos riboprobes. Each plasmid was linearized with $X h o I$, and riboprobes were generated using SP6 polymerase via in vitro transcription in the presence of ${ }^{35} \mathrm{~S}-\mathrm{UTP}$. A plasmid containing nucleotides 414-184 of the rat NGFI-A cDNA (generously supplied by J. Milbrandt, Department of Pathology, Washington University School of Medicine, St. Louis, MO) was used to generate $N G F I-A$ riboprobes. The 230-base pair $N G F I-A$ sequence was cloned into Bluescripl KS containing the T7 and T3 promolers. The plasmid was linearized with EcoRI or $B g l \mathrm{II}$ and transcribed in the presence of ${ }^{35} \mathrm{~S}$ UTP by T3 or T7 to generate sense and antisense riboprobe, respectively. A plasmid containing the full-length mouse c-jun cDNA (American Type Culture Collection, Rockville, MD) was used to generate c-jun riboprobes. The plasmid was linearized with $H i n d I I I$ or $B g l l$ and transcribed with SP6 or T7 to generate sense and antisense riboprobe, respectively. The c-fos and c-jun riboprobes were hydrolyzed to a length of $\sim 200$ nucleotides via limited alkaline hydrolysis in carbonate buffer at $60^{\circ}$ before use in the in situ hybridization protocol.

In situ hybridization. In situ hybridization was performed with $12-\mu \mathrm{m}-$ thick frozen sections that were thaw-mounted onto autoclaved gelatincoated slides. The slide-mounted sections were fixed for $10 \mathrm{~min}$ at room temperature in PBS (10 mM NaCl, $1.6 \mathrm{mM} \mathrm{NaH}_{2} \mathrm{PO}_{4}, 8.4 \mathrm{mM} \mathrm{Na}_{2} \mathrm{HPO}_{4}$, $\mathrm{pH} 7.0$ ) containing $4 \%$ paraformaldehyde, dehydrated in graded ethanols, and stored at $-80^{\circ} \mathrm{C}$. Before use, the sections were pretreated with proteinase $\mathrm{K}(10 \mu \mathrm{g} / \mathrm{ml})$ in Tris-EDTA buffer (TE: $100 \mathrm{~mm}$ Tris-HCl, 50 mM EDTA, $\mathrm{pH} 8.0$ ) at $37^{\circ} \mathrm{C}$ for $10 \mathrm{~min}$, washed in $1 \times$ TEA, $\mathrm{pH} 8.0$, for $3 \mathrm{~min}$, acetylated with acetic anhydride $(0.25 \% \mathrm{v} / \mathrm{v})$ in $1 \times$ TEA for 10 
min, washed in $2 \times \mathrm{SSC}$ for $2 \mathrm{~min}$, and dehydrated through graded ethanols $(50,70$, and $100 \%)$. The sections were then hybridized in a solution containing $50 \%$ deionized formamide, $10 \%$ dextran sulfate, $3 \times$ SSC, $5 \times$ Denhardt's, $10 \mathrm{~mm}$ DTT, $0.5 \mathrm{mg} / \mathrm{ml}$ yeast tRNA, $0.5 \mathrm{mg} / \mathrm{ml}$ heat-inactivated salmon sperm DNA, and $60 \mathrm{ng} / \mathrm{ml}{ }^{35} \mathrm{~S}$-labeled riboprobe. After overnight hybridization at $55^{\circ} \mathrm{C}$, sections were rinsed in $2 \times \mathrm{SSC}(10$ min), treated with $20 \mu \mathrm{g} / \mathrm{ml}$ RNase A $\left(37^{\circ} \mathrm{C}, 30 \mathrm{~min}\right)$, rinsed in $1 \times \mathrm{SSC}$ $(10 \mathrm{~min})$, washed in $0.1 \times \mathrm{SSC}\left(55^{\circ} \mathrm{C}, 30 \mathrm{~min} \times 4\right)$, and dehydrated in graded ethanols $(50,70$, and $100 \%)$. After air-drying, slides were mounted in $\mathrm{x}$-ray cassettes and apposed to $\beta$-max hyperfilm (Amersham, Arlington Heights, IL) for at least $3 \mathrm{~d}$, developed in D-19 (Kodak, Rochester, NY) for $5 \mathrm{~min}$, washed for $1 \mathrm{~min}$ in $1 \%$ acetic acid, and fixed with Kodak Rapid Fixer for 5 min.

\section{RESULTS}

\section{Development of kindling}

Kindling development was assessed by monitoring both behavioral and electrophysiological responses to brief, low intensity electrical stimulations applied to the amygdala twice daily. Behavioral responses consisted of limbic seizures (classes 1 and 2) and limbic and clonic motor seizures (classes 3 through 7). Electrophysiological responses consisted of electrographic seizure activity detected in EEG recordings from the amygdala electrode. Both the intensity of the current required to evoke an electrographic seizure (electrographic seizure threshold) and the duration of the electrographic seizure were measured. These experiments were performed in two sets of animals, and similar results were obtained in each set; the results of both experiments were pooled for presentation.

The development of kindling did occur in $-/-$ mice (Fig. 1), but both electrographic and behavioral features of the early stages were delayed in onset in comparison to $+/+$ mice. In $+/+$ mice, the duration of the initial electrographic seizure was $\sim 10 \mathrm{sec}$, and the duration of subsequent electrographic seizures invariably exceeded this value until reaching a steady state of at least $30 \mathrm{sec}$ by the seventeenth stimulation (Fig. 1 $A$ ). This steady increase in electrographic seizure duration (ESD) was paralleled by an increase in behavioral seizure intensity such that seizures of class 4 or 5 were evident after the eleventh stimulation (Fig. 1C). No significant difference between $+/+$ and $-/-$ in the duration of electrographic seizure evoked by the first stimulation was noted; however, in contrast to $+/+$ mice, in $-/-$ mice the duration of electrographic seizures failed to increase during the first nine stimulations before steadily lengthening thereafter (Fig. 1A). Statistically significant differences in ESD between $+/+$ and $-1-$ mice were evident with seizures induced by stimulations 2 through 12 ( $p$ values ranged from $<0.05$ to 0.001 ); the differences in response to stimulation 13 and thereafter were not statistically significant. The observed delay in lengthening of stimulus-evoked ESD was also paralleled by less severe behavioral seizures (Fig. $1 C$ ). In contrast to the attenuated responses during the earlier stages of kindling development in $-/-$ mice, no differences in electrographic or behavioral seizures were detected in the later stages of kindling development (stimulations after 16); the numbcrs of stimulations rcquircd to cvokc three seizures with a duration of clonic motor activity of at least $12 \mathrm{sec}$ were $15 \pm 2$ and $18 \pm 1$ for the $+/+$ and $-/-$ mice, respectively $(p>0.05)$. Likewise, no significant differences between $+/+$ and $-/-$ mice were found in the current required to evokc the initial electrographic seizure (not shown). Finally, no significant differences between $+/+$ and $+/-$ mice were detected in either electrographic or behavioral seizure duration (Fig. 1B,D) or any other index of kindling development.
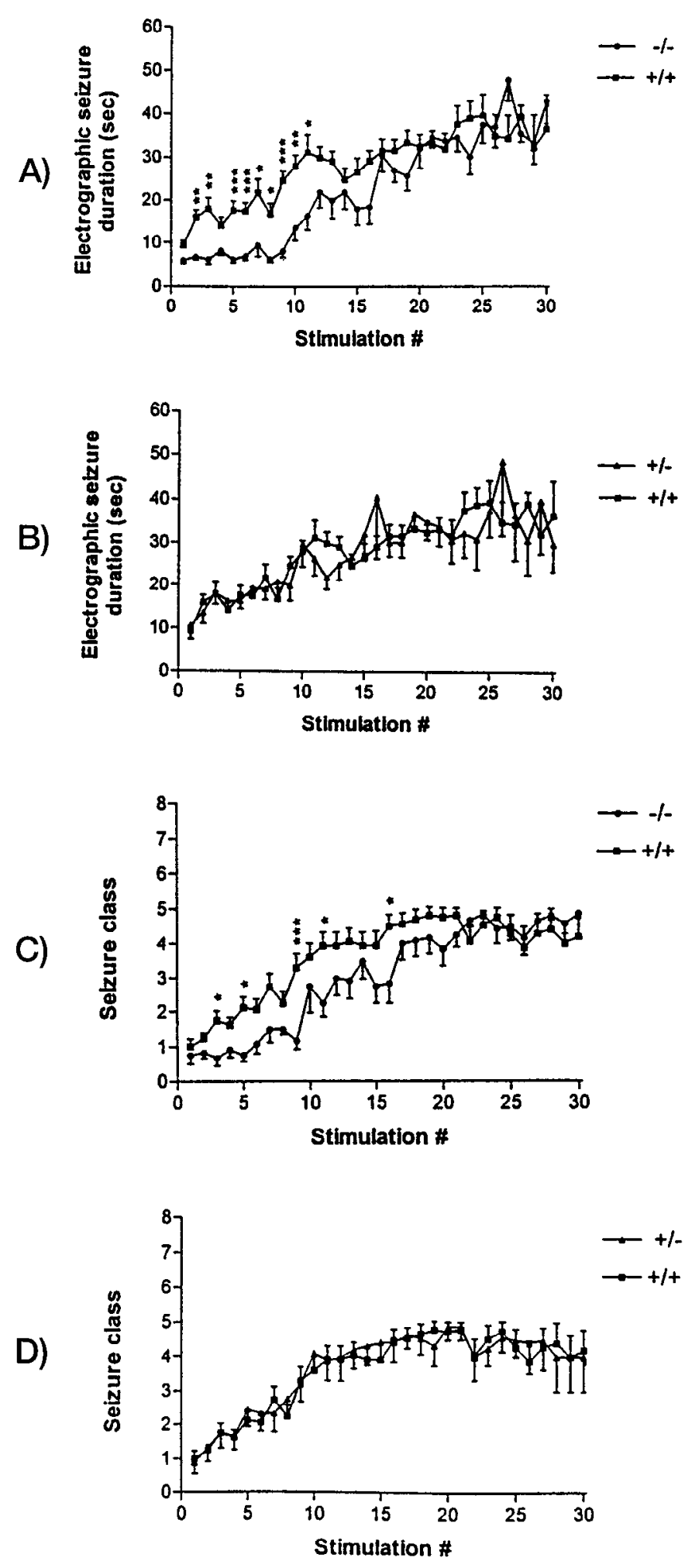

Figure 1. ESD and behavioral seizure class evoked by periodic stimulation of the right amygdala. ESD values represent mean \pm SEM of wild type $(+/+)(n=16)$, heterozygous $(+/-)(n=11)$, and homozygous $(-1-)(n=10)$ animals. Behavioral seizure class represents mean $\perp$ SEM $A, C$, Compare $+/+$ with $-1-$ animals; $B, D$, compare $+/+$ with $+/-$ animals. Data were subjected to analysis of variance with Bonferroni's post-hoc $t$ test. Single, double, and triple asterisks refer to differences of $p<0.05, p<0.01$, and $p<0.001$, respectively, found with Bonferroni's test. 


\section{Mossy fiber reorganization}

To determine whether these defects of functional plasticity were paralleled by defects of structural plasticity, we measured kindling-induced sprouting of dentate granule cell mossy fiber axons with Timm histochemistry. Significant reductions of kindling-induced increases in Timm staining in the supragranular region of the dentate gyrus were evident in -/- compared with that in $+/+$ mice (Fig. $2 A-E$ ). A fourfold increase in Timm index was evident after kindling in the $+/+$ mice compared with that in naive $+/+$ mice $(p<0.05)$ (Fig. $2 E$ ). By contrast, a smaller (2.4-fold) increase in Timm index was evident after kindling of $-1-$ mice compared with naive $-1-$ mice $(p<0.05)$. The lower level of Timm staining after kindling in $-1-$ compared with $+1+$ mice (Fig. $2 E ; p<0.05$ ) was selective to the supragranular region in that no differences in intensity were found in the infragranular region or in stratum lucidum (Fig. $2 A, C$ ) by densitometric measures (not shown). Moreover, in contrast to the overlapping valucs of Timm index among individual naive $+/+$ and $-/-$ animals, no overlap in Timm index was present among individual kindled $+/+$ compared with kindled $-1-$ animals (Fig. $2 E$ ). Kindling produced an increase in Timm index in $+1-$ animals intermediate between $+/+$ and $-1-$ animals; this increase was more variable than that of $+1+$ or $-1-$ animals (Fig. $2 E$ ) but was significant compared with naive $+/-$ controls $(p<0.05)$ and with kindled $-1-$ mice $(p<0.05)$. Timm staining in the supragranular region of naive mice was minimal and did not differ significantly among $+/+,+/-$, and $-/-$ mice (Fig. $2 E$ ).

Because mossy fiber reorganization is thought to be caused by pathological activity (i.e., electrographic seizure), meaningful interpretation of the Timm results requires that the duration of electrographic seizure be similar in the $+/+,+/-$, and $-/-$ mice. The Timm studies were performed after completion of kindling in the initial subset of animals under study $(n=16)$. These animals were stimulated until $10-15$ class 4 or 5 motor seizures had been evoked, and the total duration of evoked electrographic seizures was equivalent among the different genotypes. Animals were killed at least $3 \mathrm{~d}$ after the last seizure and prepared for morphological study. Despite differences in ESD early in kindling development similar to the composite of all animals (Fig. 1A), the total duration of evoked electrographic seizure recorded from the amygdala electrode was summed and was not significantly different among the three genotypes $(+/+, n=7 ;+1-, n=5 ;-1-, n$ $=4 ; p=0.41$ ). The lack of significant difference in the summed ESD despite differences in ESD between genotypes early in kindling development results from the fact that the ESDs in the early stages of kindling development (short individual ESDs) contribute much less to the summed ESD relative to ESDs in the later stages of kindling (much longer individual ESDs).

\section{Morphometric analyses}

Mossy fiber sprouting has been reported to occur in response to loss of neurons in the dentate hilus (Laurberg and Zimmer, 1981; Sutula et al., 1987). Furthermore, a reduction in hilar neuronal density has been described after kindling, and this has been interpreted to be attributable to loss of hilar neurons (Cavazos and Sutula, 1990; Cavazos et al., 1994). Thus the possibility arose that the reduction in mossy fiber sprouting after kindling in the $-/-$ compared with the $+/+$ mice could simply be attributable to greater loss of hilar neurons in the $+1+$ compared with the $-1-$ mice during kindling. We therefore attempted to answer the following questions. Does kindling produce a reduction in hilar neuron density (as reported previously)? If so, was the reduction in hilar neuron density attributable to a loss of neurons? Did kindling produce a greater loss of hilar neurons in $+/+$ compared with $-/-$ mice, thereby providing a potential mechanism for the observed differences in mossy fiber sprouting?

The density of hilar neurons, total number of hilar neurons, and hilar volume were measured in $+/+,+/-$, and $-/-$ mice both in unstimulated animals $(n=16)$ and after kindling $(n=16)$. Hilar neurons were identificd by the presence of nuclei containing nucleoli, as detected in cresyl violet-stained sections (Fig. 3). Because previous studies have revealed that $\sim 40 \%$ of polymorphic neurons in the rat dentate hilus contain multiple nucleoli (Cavazos and Sutula, 1990), cell counts were performed on every third section. In accordance with previous reports (Cavazos and Sutula, 1990; Cavazos et al., 1994), reductions in hilar neuron density were evident after kindling of $+/+$ mice; significant reductions were detected ipsilateral $(27 \% ; p<0.05)$ and contralateral $(26 \% ; p<0.05)$ to the stimulating electrode (Fig. 4A). Significant reductions in hilar neuron density were also found after kindling of $-1-$ mice; the magnitude of the reductions was equivalent to those found after kindling of $+/+$ mice and were similar ipsilateral $(23 \% ; p<0.05)$ and contrabateral to the stimulating electrode $(26 \% ; p<0.05)$ (Fig. $4 A$ ). Reductions in hilar neuron density were also evident after kindling of $+1-$ micc, but the differences were significant only contralateral to the stimulating electrode (Fig. 4A).

In contrast to previous studies (Cavazos and Sutula, 1990; Cavazos et al., 1994), no reductions in hilar neuron number were found after kindling of $+1+$ mice (Fig. $4 B$ ). Likewise, no reductions in hilar neuron number were detected after kindling of either $+/-$ or $-/-$ mice (Fig. $4 B$ ). Instead, to our surprise, hilar volume in $+/+$ mice was found to be increased after kindling in comparison to unstimulated $+/+$ mice (Fig. $4 C$ ); significant increases were found ipsilateral $(50 \% ; p<0.05)$ and contralateral $(40 \% ; p<0.05)$ to the stimulating electrode. Increases in hilar volume were also found in $-1-$ mice after kindling compared with unstimulated $-/-$ mice (Fig. $4 C$ ), similar in magnitude to those found in $+/+$ mice (ipsilateral, $55 \% ; p<0.05$; contralateral, $50 \%$; $p<0.05$ ). Increases in hilar volume were found in $+/-$ mice after kindling, but these did not reach statistical significance. In summary, these results replicatcd findings by Cavazos and Sutula (1990) in demonstrating kindling-induced reductions in hilar neuron density approximating $28 \%$; however, we show the reductions in neuron density reported here to be attributable to increases in hilar volume and not to reductions in hilar neuron number.

The morphometric analyses described above were performed in kindled animals and naive animals of the corresponding genotypes. In addition to kindling per se, the kindled animals had undergone surgical implantation of an electrode in the right amygdala and had been handled as a part of the kindling protocol. By contrast, naive animals had not undergone electrode implantation or handling. To determine whether electrode implantation and/or handling is sufficient to produce an increase in hilar volume, hilar volume was measured in naive $+/+$ mice and in $+/+$ mice after electrode implantation and handling with sham stimulation for 28 sessions. No differences in hilar volume $\left(\mu \mathrm{m}^{3} \times 10^{5}\right.$, mean \pm SEM, left and right, respectively; $p>0.64$ ) were detected between these animals: naive: $7377 \pm 396,7233 \pm 290$; implanted and handled: $7479 \pm 539,7055 \pm 756$.

Apart from differences induced by kindling, these detailed morphometric analyses provided an opportunity to assess the effects of the null mutation of c-fos on the anatomy of the dentate hilus. No significant differences in hilar neuron density, neuron 

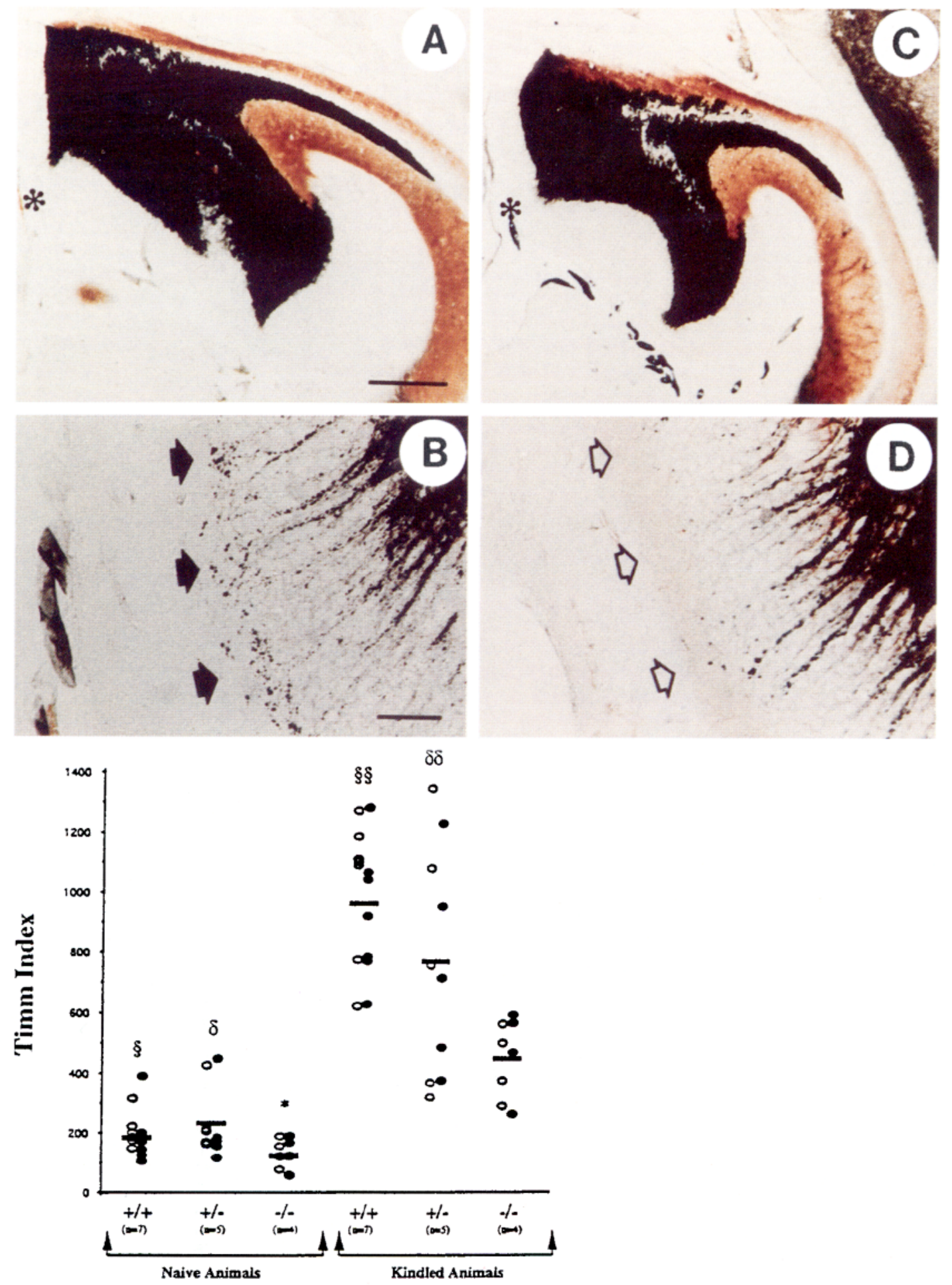

Figure 2. Timm histochemistry. Horizontal Timm-stained section of the dorsal dentate gyrus representative of a kindled $+/+(A)$ and $-/-(C)$ mouse selected from animals presented in $E$ to show the differences measured. The area near the asterisk is shown at higher magnification in panels $B(+/+)$ and $D(-/-)$, respectively; the Timm granules in the supragranular region are prominent in the $+/+$ but not in the $-/-$ mouse (arrows). Scale bars: $A$, $C, 500 \mu \mathrm{m} ; B, D, 40 \mu \mathrm{m}$. E, Results of image analysis of Timm granules in naive and kindled animals of all three genotypes $(n=7,+/+; n=5,+/-;$ $n=4,-/-)$. Timm indexes from ipsilateral and contralateral hippocampi were pooled and analyzed by two-way ANOVA with Bonferroni's $t$ test (post-hoc). $\S, p<0.05$ (vs kindled $+/+$ ); $\delta, p<0.05$ (vs kindled $+/-$ ); ${ }^{*}, p<0.05$ (vs kindled $-/-$ ); $\S \S, p<0.05$ (vs kindled $-/-$ ); $\delta \delta, p<0.05$ (vs kindled $-/-$ ). When ipsilateral and contralateral Timm scores were analyzed separately by genotype and treatment, similar differences were found. A subset of the animals undergoing kindling was used for these morphological studies; kindling development in these animals was similar to the composite of animals presented in Figure 1. 

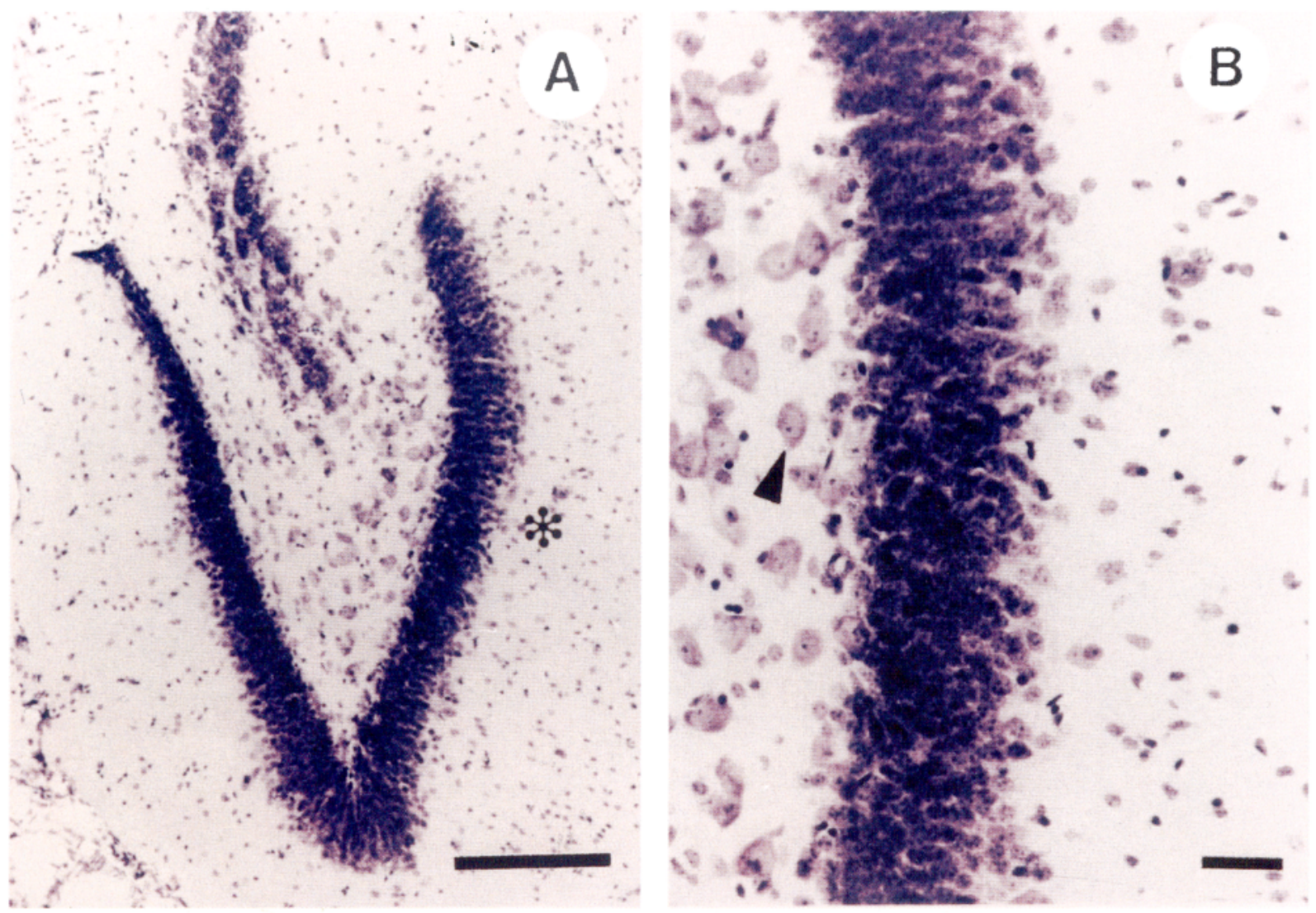

Figure 3. Cresyl violet-stained section of dentate gyrus of a $+/+$ mouse. Asterisk in $A$ demarcates region presented in higher magnification in $B$. Arrowhead in $B$ denotes a typical neuron identified by nucleolus within the nucleus. Scale bars: $A, 200 \mu \mathrm{m} ; B, 40 \mu \mathrm{m}$.

number, or hilar volume were detected as a function of genotype in either unstimulated or kindled animals (Fig. 4A-C). Importantly, the lack of detectable hilar neuron death after kindling argues against differential loss of neurons as the explanation for differences between $+/+$ and $-/-$ mice in the magnitude of kindling-induced mossy fiber sprouting.

\section{Assessment of seizure propagation into hippocampus}

Another possible explanation of the reduction of mossy fiber sprouting in $-/-$ compared with $+/+$ mice after kindling could be simply that the electrographic seizure initiated by amygdala stimulation failed to propagate to the dentate granule cells of the hippocampus in the $-/-$ compared with the $+/+$ mice. This possibility was not addressed in the initial experiments because the sole electrographic recordings were from the electrode in the amygdala, precluding direct measurement of activity in the hippocampus. This possibility was tested by two different experimental approaches, electrophysiological recordings during the stimulus-evoked seizures and in situ hybridization for IEGs in the dentate granule cells.

The critical issue addressed in these experiments was whether the ESD recorded in the amygdala provided a reliable measure of the ESD in the hippocampus in both $+/+$ and $-/-$ mice. To address this issue, the duration of electrographic seizure was compared between electrodes placed in the stimulated amygdala and the ipsilateral hippocampus during the development of kindling in both $+/+$ and $-/-$ mice. We found that each stimulationevoked electrographic seizure in the amygdala was associated with an electrographic seizure recorded from the hippocampal electrode in every $+/+$ and $-/-$ mouse. Moreover, no differences in the total duration of electrographic seizures between amygdala and hippocampus were evident in either the $+/+(n=9)$ or $-/-$ $(n=3)$ mice (data not shown). Even the brief electrographic seizure induced by the initial stimulation of the amygdala was associated with electrographic seizure in the hippocampus in both $+/+$ and $-/-$ mice (not shown). These electrophysiological recordings demonstrate that the electrographic seizure recorded from the amygdala faithfully reflected electrographic seizure propagation into the hippocampus in both $+/+$ and $-/-$ mice.

To determine whether electrographic seizure actually triggered activation of immediate early gene expression in the dentate granule cells of both $+/+$ and $-/-$ mice, in situ hybridization experiments were performed. Electrographic seizure has been demonstrated to evoke dramatic increases of transcripts for multiple IEGs in the dentate granule cells (Morgan et al., 1987; Morgan and Curran, 1991; Kiessling and Gass, 1993; Labiner et al., 1993). We therefore used in situ hybridization to test directly whether a kindled seizure evoked increases of transcripts for the IEGs NGFI- $A$ and c-jun in both $+/+$ and $-/-$ mice. In situ hybridization for both of these IEGs was performed in $+/+$ and $-/-$ mice killed $30 \mathrm{~min}$ after a class 5 kindled seizure. Striking increases in the expression of both of these IEGs were evident in every $+/+(n=5)$ and $-/-(n=5)$ mouse examined (Fig. 5). As expected, c-fos transcripts were increased in the dentate granule cells after seizure in the $+/+$ but not the $-/-$ mice (Fig. 5). Thus, these data provide direct evidence for the seizure-induced activation of IEG expression in the dentate granule cells of $-/-$ as well as $+/+$ mice, and together with the electrophysiological data (above) support the idea that equivalent amounts of pathological 
A)

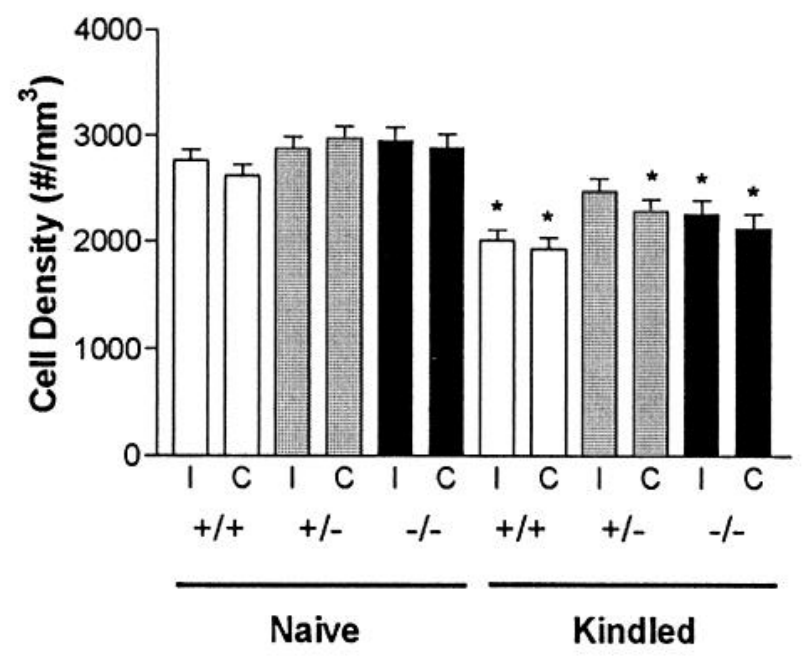

B)

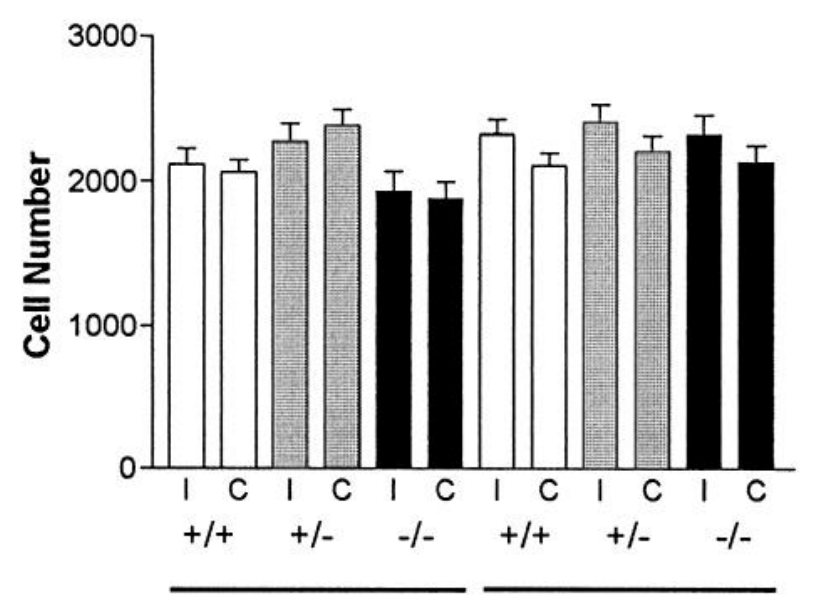

Naive

Kindled

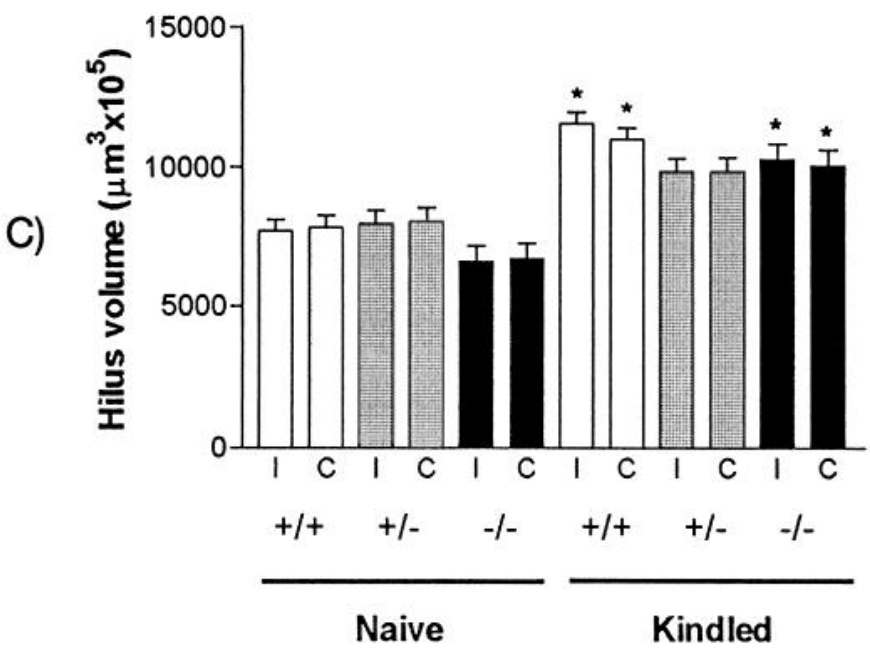

Figure 4. Morphometric analyses of cell density $(A)$, cell number $(B)$, and hilus volume $(C)$. Values represent mean \pm SEM of $+1+(n=7),+1-(n$ $=5)$, and $-1-(n=4)$ mice. Naive refers to unimplanted and unstimulated mice of corresponding genotypes. Kindled refers to treatment as described in Materials and Methods. $I$ and $C$ refer to the hippocampus ipsilateral and contralateral to the stimulating electrode, respectively. Statistical analyses were performed with two-way ANOVA with post-hoc Bonferroni's $t$ test for pairwise comparisons. ${ }^{*}, p<0.05$ in comparison to naive of corresponding genotype and side. activity invaded the dentate granule cells during the kindling protocol in the $+/+$ and $-/-$ mice. These data also verify the absence of seizure-evoked expression of $c-f o s$ in the $-/-$ mice.

\section{DISCUSSION}

Two principal findings emerge from this work. First, the development of kindling as measured by behavioral and electrophysiological indices is partially impaired in mice carrying a null mutation for c-fos. Second, kindling-induced granule cell axon sprouting into the supragranular region of the dentate gyrus as measured by Timm staining is attenuated in c-fos null mutants. Our findings support the hypothesis that expression of IEGs such as c-fos link fleeting changes of neuronal activity to lasting modifications of structure and function in the mammalian nervous system.

\section{Defective kindling-induced axonal sprouting in null mutants}

Our conclusion that there are fewer mossy fiber terminals in the supragranular region of the dentate gyrus relies on the lower level of Timm staining in this area after kindling in $-/-$ compared with $+/-$ or $+/+$ mice. The Timm method stains neural elements containing heavy metals and stains mossy fibers in particular because of their high zinc content (Danscher, 1981). Sutula et al. (1988) demonstrated the presence of Timm granules in the supragranular region after kindling and localized the aberrant Timm granules to synaptic terminals with electron microscopy. Okazaki et al. (1995) used retrograde transport of biocytin in slices isolated from rats after chemoconvulsant-induced status epilepticus to demonstrate the presence of mossy fiber synapses on granule cell dendrites in animals with robust Timm staining in the supragranular region. On the basis of these results, we conclude that the reduced Timm staining in the supragranular region of dentate gyrus reflects fewer mossy fiber terminals present in $-/-$ compared with $+/-$ or $+/+$ mice after kindling. The spatial selectivity of this effect, i.e., that the lower level of Timm staining after kindling in $-/-$ mice was confined to the supragranular region of the dentate gyrus, argues against a global effect of the null mutation on the mossy fiber axons and pinpoints the defect to an attenuation of the seizure-induced sprouting of these axons.

\section{Potential mechanisms for defective kindling-induced axonal sprouting in null mutants}

One possible mechanism for reductions of mossy fiber sprouting in $+/+$ versus $-/-$ mice could be differences in seizure-evoked hilar cell death. Reductions of hilar neuronal density have been described after kindling; these reductions have been interpreted as resulting from death of hilar neurons (Cavazos and Sutula, 1990; Cavazos et al., 1994). Thus it is conceivable that death of fewer hilar neurons in $-/-$ compared with $+/+$ mice might account for defective mossy fiber sprouting in $-1-$ mice. Cavazos and Sutula (1990) described reductions of hilar neuronal density in rats approximating $15 \%$ and $40 \%$ after 3 and 30 class 5 kindled seizures, respectively. The present findings confirm and extend these findings by demonstrating a reduction of hilar neuronal density of $\sim 30 \%$ after $10-15$ class 5 kindled seizures in $+/+$ mice. In our study, kindling did not result in any change in the total numbers of hilar neurons in $+/+,+/-$, or $-/-$ mice (Fig. $4 B$ ). In contrast to the findings of Cavazos and Sutula (1990), kindling did result in increases of hilar volume in all genotypes (Fig. $4 C$ ). Thus the reductions in hilar neuronal density described here are attributable to increases of hilar volume and not to loss of hilar neurons. Cavazos and Sutula (1990) did report a small increase of hilar volume after kindling, but this was not significant and the 


\section{c-fos $+/+$}

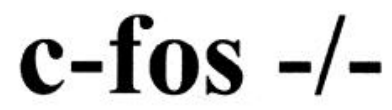

\section{NGFI-A}
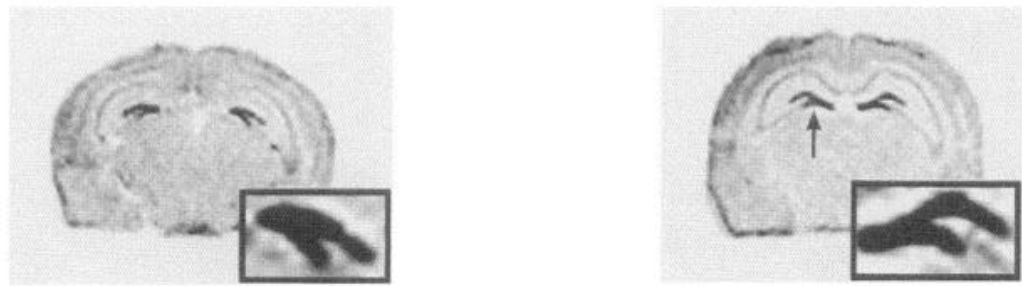

c-fos
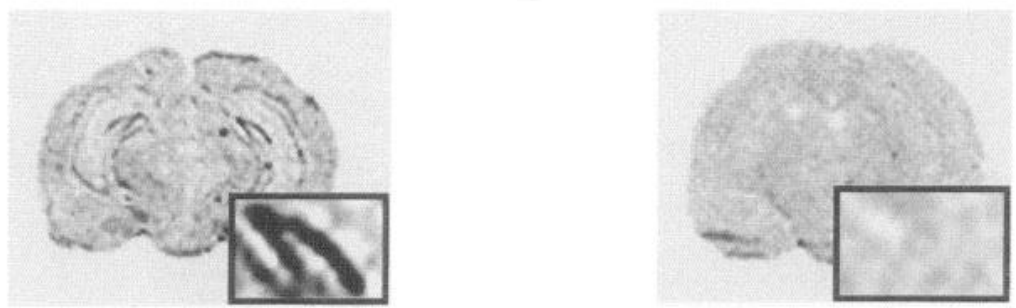

Figure 5. In situ hybridization for immediate early gene transcripts in c-fos $+1+$ versus c-fos $-/-$ animals. Representative in situ hybridization autoradiograms exposed for the same amount of time from animals killed $30 \mathrm{~min}$ after an amygdala-kindled clonic motor seizure. Arrow denotes right dentate gyrus. Insets show ipsilateral dentate gyrus at higher magnification. Marked bilateral $N G F I-A$ induction was observed in all $+/+(n=5)$ and $-/-$ $(n=5)$ animals (top), whereas as expected, only $+/+$ animals showed c-fos induction $(n=5)($ bottom). Results similar to NGFI-A were obtained with c-jun riboprobe in all 10 animals (not shown). Sense riboprobes showed no specific hybridization signal (not shown).

magnitude was not sufficient to account for the reduction of neuronal density. The explanation for the discrepancy in values of hilar volume may reside in methodological differences. Cavazos and Sutula (1990) measured the areas of the dentate gyrus in four horizontal sections and the vertical distance between these four sections by counting the number of cryostat sections of a given thickness; these measurements were used to calculate the volume. In the present study, the hilar area was measured in the 30 horizontal sections in which the neurons were counted, and the areas were integrated to determine the volume. In similar studies, Lothman and colleagues (Bertram et al., 1990; Bertram and Lothman, 1993) reported kindling-induced reductions of hilar neuronal density that were attributable to increases of hilar volume and not to loss of neurons. Although no cell loss was detectable, we cannot exclude the possibility that loss of a small population of hilar neurons escaped detection in these experiments.

The kindling-induced increases in hilar volume are reminiscent of the preferential increases in volume identified in those regions of rat neocortex undergoing greater use during development (Purves, 1994). In contrast to the effects of physiological activity on the developing normal cortex, the effects described here are the consequence of pathological activity in mature cortex. According to this developmental analogy, we favor the idea that the increases of hilar volume are attributable to kindling-induced neuropil elaboration. Other possibilities, which include glial proliferation and accumulation of fluid in the extracellular or intracellular space, warrant careful study.

Another potential explanation for impaired mossy fiber sprouting after kindling of $-/-$ mice could be that less electrographic seizure activity propagated to the dentate granule cells after amygdala stimulation in $-/-$ versus $+/+$ mice. Direct measures with recording electrodes demonstrated that total electrographic seizure activity is similar whether measured in the amygdala or the hippocampus. Furthermore, in situ hybridization experiments after amygdala-evoked kindled seizures disclosed dramatic increases in the expression of the IEGs, NGFI- $A$, and c-jun in the dentate gyrus of both $+/+$ and $-/-$ mice (Fig. 5), implying that the granule cells were indeed activated by electrographic seizure regardless of genotype.

Another explanation for the attenuation of kindling-induced mossy fiber sprouting could be that developmental absence of c-fos modifies the later ability of the granule cells to exhibit axonal sprouting in response to pathological activity in the mature brain. Ontogenetic analyses of c-fos expression argue against this possibility. First, the vast majority of dentate granule cells are born postnatally ( $\approx 85 \%$ in the rat) (Angevine, 1965; Bayer and Altman, 1974). Second, Alcantara and Greenough (1993) examined the expression of Fos immunoreactivity at multiple time points during embryonic and postnatal development and found no evidence for constitutive Fos expression in the granule cells. Rather, the dentate granule cells seem to express c-fos in response to various stimuli (such as electrographic seizure) only in the mature brain. Seizures in the immature brain induce limited or no c-fos expression (Schreiber et al., 1992) and also fail to induce mossy fiber sprouting (Sperber et al., 1991), demonstrating that activation of this genetic program is unique to the mature brain and suggesting that it is not involved in the formation of mossy fiber synapses during development. The lack of detectable differences in dentate hilar neuron density, number, or volume and the lack of difference in Timm staining among naive $+/+,+/-$, and $-/-$ animals also argue against a confounding effect of development.

Instead, we favor the explanation that the mechanism by which the null mutation of c-fos attenuates kindling-induced mossy fiber 
sprouting involves alterations of seizure-induced transcriptional regulation of gene expression in the granule cells. Seizure activity in the mature brain triggers the transcriptional activation of $\mathrm{c}-f \circ s$ and other IEGs and of genes encoding neurotrophic factors (e.g., NGF, BDNF, bFGF), neurotrophic factor receptors (e.g., Trk B, FGFR-1), and axonal growlh-assuciated proteins (e.g., GAP-43) in the dentate granule cells (Gall and Isackson, 1989; Ernfors et al., 1991; Morgan and Curran, 1991; Bendotti et al., 1993; Bengzon et al., 1993; Gall, 1993; Kiessling and Gass, 1993; Labiner et al., 1993; Meberg et al., 1993; Bugra et al., 1994; Gall et al., 1994). Such genes are excellent candidates to contribute to seizure induction of mossy fiber sprouting in the mature brain. The ability of BDNF or bFGF to selectively enhance the branching of axons but not dendrites of dentate gyrus neurons in vitro suggests that ncurotrophic factors may contribute to mossy fiber sprouting in vivo (Patel and McNamara, 1995; Lowenstein and Arsenault, 1996). Furthermore, transgenic mice overexpressing GAP-43 display spontaneous mossy fiber sprouting (Aigner et al., 1995). The presence of AP-1 sites in the regulatory elements of the bFGF (Shibata et al., 1991) and GAP-43 (Nedivi et al., 1992) promoter regions strengthens the candidacy of these particular genes in the fos-less phenotype. Although other mechanisms cannot be excluded, we believe that the absence of c-fos may limit the transcriptional activation of such growth-related genes. Alternatively, the induction of c-fos by neurotrophic factors (Bartel et al., 1989; Collazo et al., 1992) raises the possibility that the absence of c-fos may diminish responsiveness to seizure-induced neurotrophic factor expression. The potential for compensatory or adaptive effects of other members of the FOS family such as fra-1, fra-2, or fos B may explain why inhibition of this structural and functional plasticity is partial instead of complete (Pennypacker et al., 1995).

\section{Relationship of defective mossy fiber sprouting to defective kindling development}

The defective sprouting of granule cell axons may contribute to the defective kindling development of the fos-less mice. Structural or functional modifications of the granule cells may influence kindling development evoked by anygdala stimulation, because granule cell destruction is known to retard amygdaloid kindling (Dasheiff and McNamara, 1982). Synaptic reorganization of granule cell axons identified in kindled animals provides a plausible mechanism for part of the hyperexcitability of kindling (Sutula et al., 1988). Morphological and electrophysiological evidence supports the notion that at least part of the aberrant projection of the granule cell axons innervates the granule cell dendrites, thereby forming a recurrent excitatory circuit (Frotscher and Zimmer, 1983; Tauck and Nadler, 1985; Sutula et al., 1988; Cronin et al., 1992; Okazaki et al., 1995). Although a subpopulation of these aberrant axons may activate inhibitory neurons (Cronin et al., 1992; Sloviter, 1992), the enhanced synaptic excitation of the granule cells resulting from the remaining axons (Tauck and Nadler, 1985; Cronin et al., 1992) could promote the progressive intensification of evoked seizures in the kindling model. It therefore seems plausible that the attenuation of mossy fiber sprouting may contribute to the functional defects observed with kindling development; however, detailed analyses of the spatial pattern of c-fos expression during kindling development in the rat have demonstrated that c-fos expression is induced in a highly specific anatomic pattern restricted to the medial and cortical amygdaloid nuclei and pyriform cortex ipsilateral to the stimulating electrode during the first several stimulation-induced electrographic seizures (Hosford et al., 1995). If similar patterns occur in mouse and rat, perhaps the failure of the ESD to lengthen after several stimulations is attributable in part to the absence of c-fos expression in these amygdaloid nuclei and pyriform cortex. The absence of c-fos expression in the granule cells and reduced mossy fiber sprouting may then contribute to the shorter electrographic seizures and less intense behavioral seizures evoked by later stimulations. Although this explanation is plausible, our experiments do not prove that the attenuation of mossy fiber sprouting itsclf caused or contributed to the defect of kindling development.

\section{REFERENCES}

Aigner L, Arber S, Kapfhammer JP, Laux T, Schneider C, Botteri F, Brenner H-R, Caroni P (1995) Overexpression of the neural growthassociated protein GAP-43 induces nerve sprouting in the adult nervous system of transgenic mice. Cell 83:26y-278.

Alcantara AA, Greenough WT (1993) Developmental regulation of Fos and Fos-related antigens in cerebral cortex, striatum, hippocampus, cerebellum of the rat. J Comp Neurol 334:75-85.

Angevine JB (1965) Time of neuron origin in the hippocampal region. Exp Neurol [Suppl] 2:1-70.

Bartel DP, Sheng M, Lau LF, Greenberg ME (1989) Growth factors and membrane depolarization activate distinct programs of carly response gene expression: dissociation of fos and $j u m$ induction. Genes Dev 3:304-31.3.

Bayer SA, Altman J (1974) Hippocampal development in the rat. (ytogenesis and morphogenesis examined with autoradiography and lowlevel X-irradiation. J Comp Neurol 158:55-80.

Bendotti C, Vezzani A, Tarizzo G, Samanin R (1993) Increased expression of GAP-43, somatostatin and neuropeptide $Y$ mRNA in the hippocampus during development of hippocampal kindling in rats. Eur $\mathbf{J}$ Neurosci 5:1312-1320.

Bengzon J, Kokaia Z, Ernfors P, Kokaia M, Leanza G, Nilsson OG, Persson H, Lindvall O (1993) Regulation of neurotrophin and trkA and trkC tyrosine kindse receptor messenger RNA expression in kindling. Neuroscience 53:433-436.

Bertram EH, Lothman EW (1993) Morphometric effects of intermittent kindled seizures and limbic status epilepticus in the dentate gyrus of the rat. Brain Res 603:25-31.

Bertram EH, Lothman EW, Lenn NJ (1990) The hippocampus in experimental chronic epilepsy: a morphometric analysis. Ann Neurol 27:43-48.

Bugra K, Pollard H, Charton G, Moreau J, Ben Ari Y, Khrestchatisky M (1994) aFGF, bFGF and flg mRNAs show distinct patterns of induction in the hippocampus following kainate-induced seizures. Eur J Neurosci 6:58-66.

Cavazos JE, Sutula TP (1990) Progressive neuronal loss induced by kindling: a possible mechanism for mossy fiber synaptic reorganization and hippocampal sclerosis. Brain Res 527:1-6.

Cavazos JE, Das I, Sutula TP (1994) Neuronal loss induced in limbic pathways by kindling: evidence for induction of hippocampal sclerosis by repeated brief seizures. J Neurosci 14:3106-3121.

Cavazos JE, Golarai G, Sutula T (1991) Mossy fiber sprouting reorganization induced by kindling: time course of development, progression, and permanence. J Neurosci 11:2795-2803.

Cline HT, Constantine-Paton M (1990) NMDA receptor agonists and antagonists alter retinal ganglion cell arbor structure in the developing frog retinotectal projection. J Neurosci 10:1197-1216.

Collazo D, Takahashi H, McKay RDG (1992) Cellular targets and trophic functions of neurotrophin- 3 in the developing rat hippocampus. Neuron 9:643-656.

Cronin J, Obenaus A, Houser CR, Dudek FF. (1992) Flectrophysiology of dentate granule cells after kainate-induced synaptic reorganization of the mossy fibers. Brain Res 573:305-310.

Danscher G (1981) Histochemical demonstration of hcavy mctals: a revised version of the silver sulphide method suitable for both light and electron microscopy. Histochemistry 71:1-16.

Dasheiff RM, McNamara JO (1982) Intradentatc colchicine retards the development of amygdala kindling. Ann Neurol 11:347-352.

Ernfors P, Bengzon J, Kokaia Z, Persson H, Lindvall O (1991) Increased levels of messenger RNAs for neurotrophic factors in the brain during kindling epileptogenesis. Neuron 7:165-176. 
Frotscher M, Zimmer J (1983) Lesion-induced mossy fibers to the molecular layer of the rat fascia dentata: identification of post-synaptic granule cells by the Golgi-EM technique. J Comp Neurol 215:299 311.

Gall CM (1993) Seizure-induced changes in neurotrophin expression: implications for epilepsy. Exp Neurol 124:150-166.

Gall CM, Isackson PJ (1989) Limbic seizures increase neuronal production of messenger RNA for nerve growth factor. Science 245:758-761.

Gall CM, Berschauer R, Isackson PJ (1994) Seizures increase basic fibroblast growth factor mRNA in adult rat forebrain neurons and glia. Mol Brain Res 21:190-205.

Goddard GV, McIntyre DC, Leech CK (1969) A permanent change in brain function resulting from daily electrical stimulation. Exp Neurol 25:295-330.

Hosford DA, Simonato M, Cao Z, Garcia-Cairasco N, Silver JM, Butler L, Shin C, McNamara JO (1995) Differences in the anatomic distribution of immediate-early gene expression in amygdala and angular bundle kindling development. J Neurosci 15:2513-2523.

Hubel DH, Wiesel TN (1965) Binocular interaction in striate cortex of kittens raised with artificial squint. Science 28:1041-1059.

Ip YN, Li Y, Yancopoulos GD, Lindsay RM (1993) Cultured hippocampal neurons show responses to BDNF, NT3, and NT-4, but not NGF. J Neurosci 13:3394-3405.

Johnson RS, Spiegelman BM, Papaioannou V (1992) Pleiotropic effects of a null mutation in the c-fos proto-oncogene. Cell 71:577-586.

Kiessling M, Gass P (1993) Immediate early gene expression in experimental epilepsy, Brain Pathol 3:381-393.

Labiner DM, Butler LS, Cao Z, Hosford DA, Shin C, McNamara JO (1993) Induction of c-fos mRNA by kindled seizures: complex relationship with neuronal burst firing. J Neurosci 13:744-751.

Laurberg S, Zimmer J (1981) Lesion-induced sprouting of hippocampal mussy fiber collaterals to the fascia dentata in developing and adult rats. J Comp Neurol 200:433-459.

Lowenstein DH, Arsenault L (1996) The effects of growth factors on the survival and differentiation of cultured dentate gyrus neurons. J Neurosci 16:1759-1769.

Mattson MP, Murrain M, Guthrie PB, Kater SB (1989) Fibroblast growth factor and glutamate: opposing roles in the generation and degeneration of hippocampal neuroarchitecture. J Neurosci 9.3728-3740

McNamara JO, Bonhaus DW, Shin C (1993) The kindling model of epilepsy. In: Epilepsy: models, mechanisms, and concepts (Schwartzkroin P 1 , ed), pp 27-47. Cambridge, UK: Cambridge UP.

Meberg PJ, Gall CM, Routtenberg A (1993) Induction of F1/GAP-43 gene: expression in hippocampal granule cells after seizures. Mol Brain Res 17:295-297.

Morgan JI, Cohen DR, Hempstead JL, Curran T 1987 Mapping patterns of c-fos expression in the central nervous system after seizure. Science 237:192-197

Morgan JI, Curran T (1991) Stimulus-transcription coupling in the nervous system: involvement of the inducible proto-oncogenes fos and jun. Annu Rev Neurosci 14:421-451.
Nedivi E, Basi GS, Akey IV, Skene JH (1992) A neural-specific GAP-43 core promoter located between unusual DNA elements that interact to regulate its activity. J Neurosci 12:691 704.

Okazaki MM, Evenson DA, Nadler JV (1995) Hippocampal mossy fiber sprouting and synapse formation after status epilepticus in rats: visualization after retrograde transport of biocytin. J Comp Neurol 352:515-534

Patel MN, McNamara JO (1995) Selective enhancement of axonal branching of cultured dentate gyrus neurons by neurotrophic factors. Neuroscience 69:763-770.

Pennypacker KR, Hong .J-S, McMillian MK (1995) Implications of prolonged expression of Fos-related antigens. Trends Pharmacol Sci $16: 317-321$

Purves D (1994) Ncural activity and the growth of the brain. Cambridge, UK: Cambridge UP.

Racine RJ (1972) Modification of seizure activity by electrical stimulation. II. Motor seizure. Electroencephalogr Clin Neurophysiol 32:281-294.

Represa A, Jorquera I, Le Gal La Salle G, Ben-Ari Y (1993) Epilepsy induced collateral sprouting of hippocampal mossy fibers: does it induce the development of ectopic synapses with granule cell dendrites? Hippocampus 3:257-268

Schreiber SS, Tocco G, Najm I, Finch CE, Johnson SA, Baudry M (1992) Absence of $c$-fos induction in neonatal brain after seizures. Neurosci Lett 136:31-35.

Shatz CJ (1990) Impulse activity and the patterning of connections during CNS development. Neuron 5:745-756.

Shibata F, Baird A, Florkiewicz RL (I99I) Functional characterization of the human basic fibroblast growth factor gene promoter. Growth Factors 4:277-287.

Sloviter RS (1992) Possible functional consequences of synaptic reorganization in the dentate gyrus of kainate-treated rats. Neurosci Lett 137:91-96

Sperber EF, Haas KZ, Stanton PK, Moshe SL (1991) Resistance of the immature hippocampus to seizure-induced synaptic reorganization. Dev Brain Res 60:88-93.

Sutula T, He XX, Cavazos J, Scott G (1988) Synaptic reorganization in the hippocampus induced by abnormal functional activity. Science 239:1147-1150.

Sutula TP, He XX, Hurtenbach C (1987) Facilitation of kindling by CA3/CA4 lesions: evidence for epileptogenic potential of lesioninduced sprouting and synaptic reorganization. Epilepsia 28:947.

Tauck DL, Nadler JV (1985) Evidence for functional mossy fiber sprouting in hippocampal formation of kainic acid treated rats. J Neurosci 5:1016-1022.

Walicke P, Cowan WM, Ueno N, Baird A, Guillemin R (1986) Fibroblast growth factor promotes survival of dissociated hippocampal neurons and enhances neurite extension. Proc Natl Acad Sci USA 83:3012-3016.

Wang ZQ, Ovitt C, Grigoriadis AE (1992) Bone and haematopoietic defects in mice lacking c-fos. Nature 360:741-745. 